\title{
A Cognitive Analysis of Meta phorical euphemisms of death in Kenyan Newspaper Obtuaries
}

\author{
Dr. Anashia Nancy Ong'onda
}

Department of Languages and Humanities, School of Social sciences, Mount Kenya University, Thika, Kenya

\begin{abstract}
This paper examines metaphorical euphemisms of death appearing in Kenyan newspaper using the theoretical framework of Conceptual Metaphor Theory as initiated by Lakoff and Johnson (1980). Obituaries are used to publicly announce death, giving details that can be used to identify the deceased. Thus, a cognitive approach enables us to demonstrate the mitigating capacity of metaphors used as a power fulsource for euphemistic reference. Specifically, this paper investigates metaphorical expressions for death found in Kenyan obituaries, and to which conceptual mappings do these expressions belong and the cognitive processes underlying death euphemisms. Drawing on a corpus of 100 randomly death obituaries collected from the Daily Nation, and the Standard newspaper, the study found that metaphors are used as a euphemistic device for speaking about this fear-based taboo and conceptual mappings of Death in Kenyan obituaries are to some extent culture-Specific. The study found that the social cultural perceptions that the society has towards death greatly influence the language used in the writing of obituaries.
\end{abstract}

Keywords - Death euphemism, Conceptual Metaphor Theory, Obituaries, Kenyan cultural concept of Death, Kenyan Newspapers.

\section{INTRODUCTION}

Euphemism is a process of substitution where the offensive or unacceptable words are substituted by more appropriate ones. According toFowler (1957), euphemism is the use of a mild or vague or periphrastic expression as a substitute for blunt precision or disagreeable use. Leech (1974: 53) conquers with Fowler by defining euphemism as "replacing a word which has offensive connotations with another expression, which makes no overt reference to the unpleasant side of the subject". All languages have euphemistic expressions, particularly employed to avoid vulgarisms (Mey, 2001).Dancy and Davis (2004) assert that death is a "universal, natural, persistent, inescapable, unavoidable, and undeniable fact of life. Thus, Death is a www.ijels.com gnome that is feared in every social, cultural and religious circle. Among the major communicative events related to death are epitaphs, tributes, dirges, and obituaries (Moses \&Morelli, 2004).

The present study focuses on obituaries or death announcements. Death and dying are among the most referenced sematic fields in linguistic discussions of Euphemisms (Hughes, 2001). Allan and Burridge (1991: 153) have argued, that Death is "a Fear-based taboo" in which different fears coexist, namely fear of the loss of loved ones, fear of the corruption of the body, fear of evil spirits and fear of what comes after death.The term obituary is a euphemism in itself. The term 'obituary' comes from the Latin word 'obitus', meaning departure (a common euphemistic word for death). It refers to a record of announcement of death or deaths, especially in a newspaper, usually comprising a brief biographical sketch of the deceased (Fernandez, 2006).

Hernando (2001) distinguishes two types of obituaries: informative, i.e., those obituaries whose primary aim is the transmission of relevant details about the death, the deceased or the place and time of the funeral; and opinative, i.e., personal and intimate notices devoted to producing a particular effect on the readers by stressing the social status, virtues or religious fervour of the deceased. Thus, informative obituaries are objective and rely on an impersonal language devoted to perform a locutionary function, that of transmitting the relevant details of a demise. Nonetheless, opinative obituaries present a subjective nature and, by means of an emotive and figurative language, perform a perlocutionary function, that is, they are oriented towards causing a favorable impression on the reader by showing the social relevance, exemplary conduct or religious fervour of the deceased. Obituaries constitute a hybrid genre in which both information and publicity coexist, a type of discourse half way between truth and an exaggerated display of the virtues of the deceased or the grief of the surviving family members. 
Different cultures and subcultures may reveal, either consciously or unconsciously, their beliefs or understandings of death through metaphorical language. Both taboo and euphemism are linguistic devices equipped in our pragmatic competence (Hymes, 1971) and constrained in social and cultural context. A metaphorical euphemism refers to a euphemism that adopts metaphorical mapping of both source and target domains to express the notion of a forbidden domain as a result of conscious choices from pragmatic competence. Death is a fear based taboo, hence, the needfor euphemisms; that is gentle metaphorical circumlocutions for death such as passed on, passed away, no longer with us, gone. Metaphors, thus, play the role of disguising or sidestepping issues that people would rather not talk about; death being a prime example. In fact circumlocutions should be understood as evidence of death denial.

This paper, therefore, is set to investigate metaphorical euphemisms for death in terms of cognitive metaphors with a close relation to Kenyan culture. That is, metaphorical euphemism as a cognitive process of conceptualizing forbidden reality. Despite euphemisms and metaphors sharing similar characteristics, little attention has been paid to discussing the significance of metaphor as a device for euphemistic expressions. The current study, thus, is significance as it extends the existing knowledge on Conceptual Metaphor Theory (CMT). Moreover, the study contributes to the view that metaphors are cultural bound by showing the relationship between metaphors and culture. The systematic analysis of death related metaphorical expressions in "obituaries" could be used by linguist's in the classes to deepen their students' understanding of the CMT.

\section{CONCEPTUAL METAPHOR THEORY AND CONCEPTUAL MAPPINGS}

CMT introduced by Lakoff \& Johnson (1980) places metaphors initial to language. A cornerstone of the CMT is the belief that we use metaphor to structure our understanding of the world, so the locus of metaphor is not language, but thought, or the way we conceptualize one thing in terms of another (Lakoff, 1993). The theory involves a view of metaphor going beyond that of pointing to similarities between different entities or objects; instead, it is a means to create structure and organize reality(Fernandez,2006). Thus, metaphors are in fact latent in our mind, since they form part of our conception of the world; they are often used without us being aware (Goatly, 2007). That is, the system of conventional conceptual metaphor is mostly unconscious, automatic, and is used with no noticeable effort, just like our linguistic system and the rest of our conceptual system.

CMT is in fact essential to how we structure our thinking and knowledge, and to understand abstract language (Deignan, 2005). These abstract topics are understood largely or entirely through metaphors, and include those very central to our existence, such as birth, love and death (Deignan, 2005). For example, in the expression 'Our relationship has hit a dead-end street',LOVE is being conceptualized as a JOURNEY, with the implication that the love relationship is stuck because the lovers cannot go further, so they must turn back, or abandon the relationship. In a broad sense, the essence of metaphor involves understanding one domain of experiences in terms of another domain of experiences (Lakoff\& Johnson, 1980). Metaphors are especially pervasive in abstract concepts, since we rely heavily on metaphors to express abstract concepts.

Another important notion of CMT is the mapping, in which a metaphor can be understood as a mapping from a SOURCE DOMAIN to a TARGET DOMAIN. Lakoff (1993: 203) defines a metaphor as "a cross-domain mapping in the conceptual system"; in other words, a set of conceptual correspondences from a SOURCE DOMAIN(the realm of the physical or more concrete reality) to a TARGET DOMAIN(the death taboo, in our case). Kövecses (2002) develops further the idea of the conceptual metaphor. For him, a domain of experience of something is understood through another conceptual domain. Furthermore, he sees that the conceptual metaphor helps to understand the non-physical by contrasting it with physical reality (p.4).

A metaphorical mapping present's sub mappings or ontological correspondences between the SOURCE and TARGET DOMAINS as a result of reasoning about the latter using the knowledge we have about the former. For instance, in the metaphor LOVE IS A JOURNEY, the source domain JOURNEY is mapped onto the target domain LOVE. According to Lakoff (1993), there are ontological correspondences in mapping, which the aspects in LOVE (e.g. lovers, lovers' common goals, their difficulties, the love relationship, etc.) correspond to the aspects in JOURNEY (e.g. travelers, vehicles, destinations, etc).

[T] he metaphor is not just a matter of language, but of thought and reason. The language is secondary. The mapping is primary, in that it sanctions the use of source domain language and inference patterns for target domain concepts. (Lakoff, 1993: 208).

Hence, the formula of the conceptual metaphor employed by Lakoff is: $\mathrm{X}$ is $\mathrm{Y}$ or TARGETDOMAIN IS SOURCE 
DOMAIN. An example of this can bea conceptual metaphor ARGUMENT IS WAR, the statement that argument can be described in terms of war is supported by a variety of everyday metaphoric expressions such as: Your claims are indefensible; he attacked every weak point in my argument; He shot down all my arguments, etc.

So, in argument we gain or lose ground, we plan and use strategies to defend our positions, which mean that many thing sweper form in argument are often structured by the concept of war (Lakoff and Johnson,2003, 4). Another example is where, 'life' is a target domain that is conceptualised in terms of the source domain 'journeys' thus the conceptual metaphor LIFE IS A JOURNEY (Kövecses, 2002). Thus, the target domain 'life' is often understood in terms of the source domain 'journey' and we can see that there is a system of correspondences between the two domains as demonstrated below by Kövecses (2006:116).

$\begin{array}{ll}\text { Journey } & \text { Life } \\ \text { Traveller } & \text { living person } \\ \text { Departure } & \text { Birth } \\ \text { Pathways } & \text { vital choices } \\ \text { Impediments } & \text { Difficulties in life } \\ \text { Landmarks } & \text { Major life events } \\ \text { Destination } & \text { Death }\end{array}$

Figure 1: The source domain 'journey' is mapped onto the target domain 'life

Figure 1 above shows that constituent conceptual elements from journeys correspond to constituent elements of life: living persons correspond to travellers; birth and death correspond to starting point and destination; vital choices correspond to pathways; difficulties in life correspond to impediments to travel and major life events correspond to landmarks along a journey (Deignan, 2005; Kövecses, 2002; Lakoff, 1993). Journey' is essential to our understanding of the concepts of life and love. In effect, metaphors "impose" meanings on structures of reality, thereby creating reality in each language and culture. Other languages may thus understand life and love in terms of different domains than journeys.

Lakoff and Johnson (1980), Lakoff (1993), Deignan (2005) andKövecses (2008) agree that metaphor is grounded in human embodied experience. That is, since conceptual metaphors are our thoughts, they are highly related to our experience which shapes our thoughts. Cognitive metaphor theorists have shown that cognitive metaphors come from our everyday experience.

Gibbs and Wilson (2002 in Deignan, 2005) also argue that many metaphor themes that are about emotions have risen from body experience. The advantage of mappings of concrete daily experience onto an abstract idea is that it www.ijels.com enables the human mind to quantify, visualize and generalize about the abstract through metaphor, because it makes use of the source domains that we know well from our concrete experience. Thus, our metaphor system is central to our understanding of experience and to the way we act on that understanding. The current study focuses on metaphorical euphemism of death.

\section{KENYAN CULTURAL CONCEPT OF DEATH AND METAPHORS}

According to Lakoff (1993: 245), 'Metaphorical mappings vary in universality; some seem to be universal, others are widespread, and some seem to be culture specific.' Kövecses's Metaphor In Culture (2005) presents a detailed discussion of what kinds of metaphor are potentially universal or near-universal, which aspects of metaphor are involved in variation, how and why conceptual metaphors are both universal and culture-specific, and it also gives and compares examples of different languages to show the potential universality of metaphor and the differences presented in different languages and cultures and so on. Thus, Metaphorical mappings vary in universality; some seem to be universal, others are widespread, and some seem to be culture- specific. Following Kovesce's suggestions the current paper explores the concept of death euphemism in close relation to Kenyan culture.

According to the Kenyan belief system, life does not end with death, but continues in another realm. However, when death occurs, there is usually an impact on the family and friends of the deceased, the magnitude often depends on whether death was expected or unexpected. According to Eyetsemitan (2002), the traditional African belief system is also referred to as ancestor worship and is based on an understanding that the life course is cyclical and not linear. Based on this system of belief, those who are dead are alive in a different world and can reincarnate (and return to this world) in new births. Thus, in Kenyan context death is seen as a continuation of life in another world. That is, an individual lives in a spirit world, receiving a new body which is identical to the earthly body, but with the capacity to move about as an ancestor. Lending credence to the African concept of death, Dancy and Davis (2006) assert that death indicates the physical separation of the individual from other humans.Kövecses (2005) suggests that: Universal experiences do not necessarily lead to universal metaphors. Therefore Death being a universal experience may be perceived differently by different cultures. Moreover,euphemism is cognitively inhibited hence different languages and culture may vary in how this semantic domain is conceptualized. The current study, 
therefore, explores Death Euphemism in Kenyan obituaries. Moreover,

\section{RESEARCH METHODOLOGY}

The data used for the research are taken from Kenyan media outlets; namely; The Nation and The standard newspaper published during the year of 2016. The Nation and The standard newspaper were chosen as a research field because of their popularity in Kenya.Given the domains of relationship and death being interconnected culturally, metaphorical death euphemisms are analyzed from the approach of descriptive sociolinguistics. The study was guided by the following research questions:

1. Which metaphorical euphemisms of death can be found in Kenyan obituaries, and to which conceptual mappings do these expressions belong?

2. What cognitive processes underlie death euphemism?

\section{RESULTS AND DISCUSSIONS}

5.1 Metaphorical euphemisms of Death in Kenyan obituaries and Conceptual Mappings

5.1.1 Death as a journey to an after world mapping DEATH AS A JOURNEY TO AN AFTER WORLD mapping is the largest mapping with $52 \%$ of the metaphors found in the data collected. The act of dying corresponds to the act of leaving; the destination corresponds to an encounter with God in Heaven and the dying person corresponds to a traveller. Thus, DEATH AS JOURNEY TO AN AFTER WORLD mapping involves understanding one domain of experience, DEATH, in terms of a very different domain of experience, JOURNEYS.DEATH AS JOURNEY metaphor can be understood as a mapping from a source domain (in this case, journey) to a target domain (in this case, death).Following Lakoff and Johnson (1980) CMT theory, mappings in conceptual system are named using mnemonics which suggest the mapping. Mnemonic names typically (though not always) have the form: TARGETDOMAIN IS SOURCE-DOMAIN, or alternatively, TARGETDOMAIN AS SOURCEDOMAIN. In this case, the name of the mapping is DEATH IS A JOURNEY. Thus, DEATH IS A JOURNEY metaphor is a mnemonic for a set of ontological correspondences that characterize a mapping of DEATH-AS-JOURNEY. In the data collected from the Kenyan obituaries it was noted that the dead person was described as a traveller as shown below:

\section{Example 1}

www.ijels.com
It is with deep sadness that we inform you of the untimely passing away of our beloved mum[... ] Mum went to be with the Lord on the 22nd of June, 2016.

\section{Example 2}

We are grieved to announce the passing on to glory of John Kamau Kamwanya village who went to meet his heavenly family

\section{Example 3}

It is with much sadness but with humble acceptance of God's will that we announce the promotion to Glory of Lucy Mukhwana that departed us on Tuesday $2^{\text {th }}$ September 2016.

\section{Example 4}

Our dear mother Mary Anyango has passed from this life into the loving arms of Jesus her savior and Lord. We give thanks to God for her life which was lived to his glory...Please come and celebrate her life with us.

\section{Example 5}

We regret to announce the sudden death of Mr Peter Gaturu Kamuria of Coventry, who went to be with the Lord on Friday 12th February, 2016

\section{Example 6}

We celebrate the life of Loise Wanjiku Platt who passed away on 19th January after a long illness bravely.

The data above shows that the movement of the dead person more clearly acquires characteristics of a journey. Thus, the dying person corresponds to the traveller, 'dying' corresponds to the act of leaving, while the destination (if included) is generally an encounter with God as shown in Example 1 (Mum went to be with the Lord), 2(who went to be with his heavenly family)and 4 (has passed from this life into the loving arms of Jesus her Saviour and Lord).Moreover example 1 to 4 show death as movement or shift from one container (Active state) into a different container (a permanent motionless state). Example three shows (death as a promotion to Glory).Moreover, the above examples shows path schema underlies metaphorical concepts of death. The world is conceptualized as container and death is going out of it, and entering the hereafter world as shown by phrases such as(who went to be with the Lord, has passed from this life into the loving arms of Jesus, and who went to meet his heavenly family).

Thus, the general mapping DEATH AS JOURNEY is grounded in the experience of the surrounding people not being able to sense the dead person anymore, and that the 
person has supposedly moved, or has been moved by someone or something (Bultinck, 1998). Kenyan obituaries, thus, shows believe in life after death to an afterworld (heaven) hence giving the surviving relatives comfort. Moreover, a second reason to include a destination may be a wish to mitigate the fear of having a meaningless death (cf. Allan \&Burridge, 1991) by giving the dead a "purpose" of dying; in this case they are meeting someone (God). Moreover, sentiments such as passed away/passing on, Fade/slip away, preceded in death shows metaphorical euphemisms where death is conceptualized through the source domain of MOVEMENT.The general mapping DEATH IS MOVEMENT is grounded in the experience of the surrounding people not being able to sense the dead person anymore, and that the person has supposedly moved, or has been moved by someone or something (Bultinck, 1998). According to Gross (1985: 206), however, the strongest appeal of pass away, and by extension passing (n), does not come from its vagueness in meaning and experiential basis, but from its intimations of tranquillity. Thus, metaphorical circumlocution of death clearly shows that human beings are reluctant to deal with the subject of death using straightforward terms.

\subsubsection{DEATH AS A LOSS}

Death is also seen as loss to family and friends. This mapping follows the categorization presented by Bultinck (1998), where death is viewed as the loss of the valuable possession life. Death as a loss includes expressions of feelings from the surviving relatives and friends, such as regret, deep sorrow, andgreat sadness that are effects of loss. $48 \%$ of the data collected showed DEATH AS A LOSS. Example 4 to 7 shows expressions of loss by the surviving relatives.

\section{Example 7}

We regret to announce the passing of our beloved daughter, sister and friend, $[\ldots]$

\section{Example 8}

It is with deep sorrow we announce the death of ...

\section{Example 9}

It is with great sadness that we announce the demise of ...

\section{Example 10}

It is with a profound sense of sorrow that we announce the untimely demise of...

Example 11The family of Christine and Edward of Manchester UK, regret the untimely passing of their dad www.ijels.com
The above data shows that from the perspective of the survisors, those left behind (relatives and friends0; death may be conceptualized as a loss, either of a dear person, or life itself. Such a loss is often characterized as irreparable and unredeemable in Kenyan context as demonstrated by the following metaphorical euphemisms: his death is an irreparable loss and no one can replace the love she gave us. Moreover an expression such as the late and beloved also shows DEATH AS FEELINGS CONCERNING THE DEAD.

\section{Example 12}

The body of the late Steve Kimemia Njiru will leave Chiromo mortuary...

The late is short for 'the late lamented', or 'the late(ly) regretted' (Rawson, 1981: 162), which are expressions of grief towards the dead. Death is, therefore, conceptualized as the feeling of grief experienced by the survivors because the expression semantically means 'recently died

\subsubsection{DEATH AS REST OR SLEEP}

Death is quite often conceptualized as a sleep or rest after a toilsome life. $100 \%$ of the data collected depicted death as rest and sleep. DEATH IS SLEEP and DEATH IS REST have a large set of matching correspondences between the target domain 'DEATH' and the source domain of 'SLEEP' or 'REST'as shown in the following examples:

\section{Example 13}

Lucy took her last breath and died peacefully on $24^{\text {th }}$ December 2016 at 9 am surrounded by her family members.

\section{Example 14}

Loise will be Laid to rest on Friday 27th January. The Cortege leaves Lee Funeral Home at 9.00 am for a memorial Service at PCEA Lang'ata Church at $10.30 \mathrm{am}$. This will be followed by the interment at Lang'ata.

\section{Example 15:}

Rest in peace mum.

\section{Example 16:}

Sleep peacefully ShoSho (Granny)

In Kenyan context the body of a dead person appears like of a sleeping person with silence and stillness. Thus, the place where a person is buried, their grave, is conceptualized as a place of eternal/last/long sleep or the final resting place, the 
eternal resting place, the long resting place, etc.).These metaphorical euphemisms of DEATH as SLEEP and REST reflect people's attempts to come to terms with death as shown in Example 13 to 16 . The metaphor to die is to rest or sleep suggests the conceptualization of death as sleep. The perceptual association of death and sleep and rest is grounded in our embodied experiences, and thus the concept of SLEEP naturally becomes the source domain of DEATH for euphemistic purposes. Moreover, metaphorical euphemisms of death are related to being void of breath as shown in Example 13.This demonstrates Fan's (2006: 72) assertion that the aspects of SLEEP as mapped on to the target domain, DEATH, are those which provide consolation for those who are left behind, thus euphemistically highlighting the neutral aspects of SLEEP "while other aspects of DEATH such as sorrow, horror are hidden". Thus, the mapping of DEATH IS SLEEP is seen as Physiological effect of death.

\subsection{Cognitive processes in Death Euphemisms}

\subsubsection{Conceptual Personification}

Lakoff and Turner (1989: 15-17) argue that death is personified in different ways, for example as grim reaper, as someone trying to catch you, as a warrior battling you, a beast trying to devour you, or your opponent in a chess match or as adestroyer. Some of these personifications derive from another conceptual metaphor. On the other hand, "[d]eath is an event and this event can be conceptualized as an action via the EVENTS ARE ACTIONS metaphor" (Kövecses 2002:229). The event, in the case of death, is "cutting down people with a scythe or simply appearing before the people whom he wants to die." (Kövecses 2002: 229). In the data collected the mapping of DEATH IS PROMOTION TO GLORY, DEATH IS REST and DEATH IS SLEEP, DEATH IS GOD'S WILL were reflected as shown in the data below:

\section{Example 17}

It is with humble acceptance of God's will that we announce the passing on to glory of Mr. Kamau which occurred on Monday $28^{\text {th }}$ November, 2016 back in Kenya.

\section{Example 18}

The Wairia's family wish to announce the promotion to glory of their beloved mother, Mrs Ruth Wambui Wairia on Monday $15^{\text {th }}$ August 2016.

\section{Example 19}

It is with humble acceptance of God's will that we announce the passing on to Glory of our mum, Esther Onyango on $16^{\text {th }}$ March 2016

www.ijels.com

\section{Example 20}

It is with great sadness we inform and confirm to you the suden death of John Olum on Sunday $10^{\text {th }}$ April 2016...He will be laid to reston Friday $22^{\text {nd }}$ April ....

\section{Example 21}

It is with great sadness we announce the departure of our dad Mr. Kuria Gatonye of Karinga Village

\section{Example 22}

We announce the promotion to glory of Reverend Kathleen Kariko Wiliams who was picked to join other angels in heaven on

Thus, the researcher concludes that death metaphors highlight some aspects as they hide others through personification. The aspect of REST and SLEEP hides the pain and sorrow that comes with death as the aspect of REST and SLEEP are highlighted. This is in tandem with an important idea in CMT that relates to hiding and highlighting. In this line, Evans and Green (2006:303) believe that "when a target is structured in terms of a particular source, this highlights certain aspects of the target while simultaneously hiding other aspects". For example, in the personification of death in the collected data, In DEATH IS SLEEP metaphor, the inactiveness and inattentiveness of the corpse is highlighted. In DEATH IS DEPARTURE metaphor, the onset of dying is concentrated on. In DEATH IS PROMOTION TO GLORY and GOD'S WILL the personifications highlight the power and control of death over people.Thus, in highlighting the focus of a source on a target is partial (cf. Kövecses, 2010). Only a part of a source is used for highlighting and this process is called the partial metaphorical utilization.

\subsubsection{Metonymy}

Metonymy is defined by Lakoff (1987: 78) as a stand-for relation who exists in only one particular Idealized Cognitive Model (ICM). That is, one kind of entity stands for another kind of entity. The entity that direct attention, or provide mental access to another entity is called the vehicle entity, and the kind of entity to which attention, or mental access is provided is target entity. Thus, Metonymy is a cognitive process in which one conceptual entity, the vehicle, provides mental access to another conceptual entity, the target, within the same domain, or ICM(Kövecses,2010). 
Example 23

We wish to announce the death of Florence Amimo, whose family humbly accepts God's will to promote her to everlasting Glory.

\section{Example 24}

The Omolo's family wish to announce the demise of our beloved father Mzee Albert Omolo who was promoted to Glory on the $1^{\text {st }}$ August 2016 after a long illness

In Example 23 and 24 we mentally access the concept of DEATH via a salient part GLORY. EVERLASTING GLORY and PROMOTION TO GLORY is a conceptually salient reference point in that here they stand for death or an end to life or a permanent situation. Thus, GLORY stands for DEATH itself. This suggests that in this metonymy, one entity or thing is used to indicate, or to provide mental access to another entity. That is, GLORY is the vehicle concept and DEATH is the target. This confirms Lakoff\& Turner (1989) view that metonymy is as a type of conceptual mapping. Therefore, metonymy is a cognitive tool used for conceptualization rather than a merely linguistic strategy or a rhetorical device.

\subsection{Conclusion}

This study is an attempt to investigate metaphorical euphemism of death in Kenyan newspaper obituaries from the perspective of cognitive linguistic. Through the analysis of linguistic metaphorical and metonymic expressions of death euphemisms, this study found that death is realized both metonymically and metaphorically. The metaphors of personification were found to be more influential as shown through the metaphorical mapping. The study found that death target is understood through different source concepts such as Journey, as an afterworld, sleep, rest and loss. The study found that Death has control over human and hence the need of Death Euphemisms that help people talk about this gnome that is feared in every social, cultural and religious circle. Thus, in some way death was seen as journey to everlasting glory that was perceived to be much better than life. The study also found that cognitive processes such as personification and metonymy are important aspects that people use to perceive themselves and the abstract outside world such as death. The study also demonstrates the universality and relatively of metaphors and metonymies in human conceptual system. Therefore, the study concludes that semantic devices such as metonymies and personification play a significant role in the formation of euphemistic substitutes for the notions of death and dying.

\section{REFERENCES}

[1] Allan, K. \& Kate B. (1991).Euphemism and Dysphemism: Language Used as Shield and Weapon. Oxford: Oxford University Press.

[2] Bultinck, B. (1998). Metaphors We Die by: Conceptualizations of death in English and their implications for the theory of metaphor. Antwerpen: University of Antwerp.

[3] Dancy, J, \& Davis W. D. (2006).Key Topics on Endof-Life Care. Derived from the Last Miles of the Way Home Nation Conference to Improve End of Life Care for African mericans. In Collaboration with the Duke Institute of Care at the End of Life. Family and Psychosocial Dimensions of Death and Dying in African Americans; pp. 187-211.

[4] Deignan, A. (2005). Metaphor and Corpus Linguistics. Amsterdam: John Benjamins Pub.

[5] Evans, V.\& Green, M. (2006). Cognitive Linguistics: An Introduction. Edinburgh: Edinburgh University Press.

[6] Eyetsemitan, F. (2002). Cultural Interpretation of Dying and Death in a non-western Society: The Case of Nigeria. Available from: http://dx.dx.doi.dx.doi.org/10.10.9707/2307-23070919.2307-0919.1090

[7] Fernández, E. C. (2006). The Language of Death: Euphemism and Conceptual Metaphorization in Victorian Obituaries.In SKY Journal of Linguistics 19:101-130.

[8] Fowler, H. (1957).A dictionary of Modern English Usage. Oxford: Oxford University Press.

[9] Gibbs, R. (1994). The poetics of mind: figurative thought, language, and understanding. Cambridge: Cambridge University Press.

[10] Goatly, A. (2007). Washing the brain. Amsterdam/Philadelphia: John Benjamins Publishing Company.

[11] Gross, J. (1985). "Intimations of Mortality." In D. J. Enright,Fair of Speech: The Uses of Euphemism, pp. 203-219. Oxford; New York: Oxford University Press.

[12] Kövecses, Z. (2008). Metaphor and Emotion.In R. Gibbs (ed.),The Cambridge Handbook of Metaphor and Thought, pp.380-396.Cambridge: Cambridge University Press.

[13] Kövecses, Z. (2010). Metaphor: A Practical Introduction, $2^{\text {nd }}$ Ed. Oxford:Oxford University Press.

[14] Hernando, B. M. (2001). "La muertemensajera . Las sequel as de defunción Comoelementoin for mativo". 
[http://www.ucm.es/info/perioI/Period_I/EMP/Numer _07/7.5-Inve/7-5-03.htm]

[15] Hughes, G. (2000). A history of English words. Oxford: Blackwell.

[16]Hymes, Dell. (1971). Sociolinguistics and the ethnography of speaking.In Social anthropology and language, ed. by Edwin Ardener, 47-93. London: Routledge.

[17] Kövecses, Z. (2002). Metaphor: A Practical Introduction. Oxford: Oxford University Press.

[18] Kövecses, Z. (2005). Metaphor in Culture: Universality and variation. Cambridge: Cambridge University Press.

[19] Kövecses, Z.2006. Language, mind, and culture. Oxford: Oxford University Press.

[20]Lakoff, G. \& Johnson, M. (1980). Metaphors We Live By. Chicago: The University of Chicago Press.

[21] Lakoff, G. (1987).Women, Fireand Dangerous Things. Chicago: The University of Chicago Press.

[22] Lakoff, G, \& Turner, M. (1989).More Than Cool Reason: A Field Guide to Poetic Metaphor. Chicago \& London: The University of Chicago Press.

[23]Lakoff, G. (1993).The Contemporary Theory of Metaphor. In Andrew Ortony (ed.), Metaphor and Thought (2nded.), pp. 202-251. Cambridge: Cambridge University Press.

[24] Leech, G. (1974). Semantics. Harmonds worth: Penguin

[25] Mey, J. L. (2001). Pragmatics. An Introduction. Maiden, MA: Blackwell.

[26] Moses, R. \&Marelli, G. (2004).Obituaries and discursive construction of dying and living.Texas Linguistic Forum47: 123-130 